\title{
The Mediatorless Electroanalytical Sensing of Sulfide Utilizing Unmodified Graphitic Electrode Materials
}

\author{
Bhawana Thakur ${ }^{1,2}$, Elena Bernalte ${ }^{2,3}$, Jamie P. Smith ${ }^{2}$, Patricia E. Linton ${ }^{4}$, Shilpa N. Sawant ${ }^{1}$, \\ Craig. E. Banks ${ }^{2}$ and Christopher W. Foster ${ }^{2, *}$ \\ 1 Chemistry Division, Bhabha Atomic Research Centre, Mumbai 400085, India; \\ bhawana_bhanupratap@yahoo.co.in (B.T.); stawde@barc.gov.in (S.N.S.) \\ 2 Faculty of Science and Engineering, School of Science and the Environment, Division of Chemistry and \\ Environmental Science, Manchester Metropolitan University, Chester Street, Manchester M1 5GD, UK; \\ ebernaltemorgado@gmail.com (E.B.); smith.jamiep@gmail.com (J.P.S.); C.Banks@mmu.ac.uk (C.E.B.) \\ 3 Departamento de Química Analítica e IACYS, Facultad de Ciencias, Universidad de Extremadura, \\ Avda. De Elvas s/n, Badajoz 06006, Spain \\ 4 Faculty of Science and Engineering, School of Science \& the Environment, Division of Biology and \\ Conservation Ecology, Manchester Metropolitan University, Chester Street, Manchester M1 5GD, UK; \\ P.E.Linton@mmu.ac.uk \\ * Correspondence: chris.w.foster@mmu.ac.uk; Tel.: +44-016-1247-2000
}

Academic Editors: I. Francis Cheng and Trevor Davies

Received: 5 February 2016; Accepted: 11 April 2016; Published: 16 April 2016

\begin{abstract}
The mediatorless electroanalytical sensing of sulfide is explored at a range of commercially available graphitic based electrodes namely, edge and basal plane pyrolytic graphite (EPPGE and BPPGE, respectively), boron-doped diamond (BDDE), glassy carbon (GCE) and screen-printed electrodes (SPE). The electrochemical performance is evaluated in terms of current density/analytical signal and oxidation potential, where the GCE and SPE are found to possess the optimal electrochemical responses. The electroanalytical performance of the GCE is explored towards the electrochemical sensing of sulfide and it is found that it is hampered by sulfide passivation, thus requiring pretreatment in the form of electrode polishing between each measurement. We demonstrate that SPEs provide a simple analytically comparable alternative, which, due to their scales of economy, create disposable, one-shot sensors that do not require any pretreatment of the electrode surface. To the best of our knowledge, this is the first report using mediatorless SPEs (bare/unmodified) towards the sensing of sulfide. In addition, the electroanalytical efficacy of the SPEs is also explored towards the detection of sulfide within model aqueous solutions and real drinking water samples presenting good apparent recoveries, justifying the plausibility of this graphitic mediatorless screen-printed platform.
\end{abstract}

Keywords: sulfide; graphitic electrodes; screen-printed electrodes

\section{Introduction}

Over recent decades, the importance of monitoring the level of sulfide has become an extremely important focus, especially from both environmental and medical diagnostic points of view. Current methods for the detection of sulfide usually rely upon colorimetric measurements (i.e., zinc trap/methylene blue test) or a visual color coded detection using a paper strip [1]. Although there are several methods reported within the literature for the analytical sensing of sulfide (within aqueous media) such as chromatography, mass spectrometry, fluorescent and chemiluminescent techniques [2-7], electroanalytical techniques can provide potentially sensitive, portable and low cost alternatives [8-13]. There have been several reports upon the electroanalytical sensing of sulfide within aqueous media, however many involve multiple arduous and time-consuming fabrication steps 
and in the majority of these reports, electrocatalysts/mediators are employed for the electrochemical sensing of sulfide; Table 1 provides a thorough overview of literature. For example, recent work has been published utilizing nano-copper screen-printed electrodes (SPEs) for the successful detection of sulfide [14].

From inspection of Table 1, it is surprising that bare SPEs have been overlooked for the direct oxidation of sulfide, especially as SPEs have revolutionized the electroanalysis field due to their ability to bridge the gap between laboratory experiments and in-field implementation [15-18]. Screen-printing technology permits the mass production of highly reproducible electrode configurations and, due to its scales of economy, inexpensive electrochemical sensing platforms can be readily fabricated [19-21].

In this paper, the mediatorless electroanalytical sensing of sulfide utilizing a range of commercially available carbon based electrodes are evaluated. The electrochemical performance of each electrode is explored in terms of current density and oxidation potential, where the glassy carbon (GCE) and SPEs are found to give rise to optimal responses. However, the GCE is hindered by the passivation of sulfide thus requiring pretreatment (in terms of electrode polishing) before every measurement. Due to the simple, disposable, one-shot nature of SPEs, they provide a competitive alternative to the GCE and overcome the issue of pretreatment. The electroanalytical sensing of the sulfide using SPEs in model aqueous solutions is explored and to the best of our knowledge this is the first report of a mediatorless approach to the sensing of sulfide utilizing bare/unmodified SPEs. The electroanalytical efficacy of SPEs is additionally explored towards the sensing of sulfide within real drinking (tap) water samples with good apparent recoveries. 
Table 1. An overview of literature reports concerning the electrochemical detection of sulfide within aqueous media.

\begin{tabular}{|c|c|c|c|c|c|c|c|}
\hline Electrode Modification & Underlying Electrode & Technique & $\begin{array}{c}\text { Sensitivity/ } \\
\mu \mathbf{A} \cdot \mathbf{m M}^{-1} \cdot \mathbf{c m}^{2}\end{array}$ & $\operatorname{LOD}(3 \sigma) / \mu \mathrm{M}$ & $\begin{array}{c}\text { Linear } \\
\text { Range/ } / \mu \mathrm{M}\end{array}$ & Comments & Reference \\
\hline $\begin{array}{l}\text { Copolymer of anthracene and } \\
\text { ferrocene }\end{array}$ & BPPG & $\mathrm{CV}$ & $\gamma$ & $\gamma$ & $200-2000$ & Dual sensor for $\mathrm{pH}$ and sulfide. & [22] \\
\hline Ferrocene carboxylate & GCE and BDDE & $\mathrm{CV}$ & $81.4 \times 10^{3}$ & 2.0 & $200-1000$ & $\begin{array}{l}\text { Ferrocene carboxylate used as electrocatalyst. Detection of } \\
\text { sulfide within river water samples reported. }\end{array}$ & [23] \\
\hline Quercetin & Pencil graphite electrode & $\mathrm{CV}$ & $41.0 \times 10^{3}$ & 0.3 & $1-20$ & $\begin{array}{l}\text { Quercetin used as electrocatalyst for sulfide oxidation. Sulfide } \\
\text { detected in waste waters and validated with an independent } \\
\text { spectrophotometric method. }\end{array}$ & [24] \\
\hline $\begin{array}{l}\text { Hexadecylpyridiniumbis } \\
\text { (chloranilato)-antimonyl(V) }\end{array}$ & SPE & $\mathrm{CV}$ & $\gamma$ & $\gamma$ & $0.01-0.70$ & $\begin{array}{l}\text { Hexadecylpyridinium-bis(chloranilato)-antimonyl(V) acted as } \\
\text { an electrocatalyst for the sensing of sulfide. }\end{array}$ & [25] \\
\hline Ferrocene sulfonate & BDDE and GCE & $\mathrm{CV}$ & 70.7 & 14.0 & $20-1000$ & $\begin{array}{l}\text { Ferrocene sulfonate acted as used as an electrocatalyst for the } \\
\text { sensing of sulfide. }\end{array}$ & [26] \\
\hline Ionic liquid & SPE & Amperometry & 41.0 & $12.9 \times 10^{-3}$ & $1-3000$ & $\begin{array}{l}\text { Ionic liquid used to immobilize ferricyanide as an } \\
\text { electrocatalyst. Sulfide detected in hot spring water and } \\
\text { ground water. }\end{array}$ & [27] \\
\hline CNT & GCE & Amperometry & $16.2 \times 10^{2}$ & 0.3 & $1-112$ & Sulfide detected in river water samples & [28] \\
\hline Alkylated ferrocene & BDDE & $\mathrm{CV}$ & $\gamma$ & $\gamma$ & $\gamma$ & Alkylated ferrocene sulfonates used as electrocatalyst. & [29] \\
\hline $\begin{array}{l}\text { DMPD } \\
\text { DPSA } \\
\text { DDPS }\end{array}$ & GCE & $\mathrm{CV}$ & $\begin{array}{c}54 \times 10^{-5} \\
11.3 \times 10^{-5} \\
22.85 \times 10^{-5}\end{array}$ & $\begin{array}{c}3.0 \\
5.3 \\
12.3\end{array}$ & $\begin{array}{c}3-150 \\
5-150 \\
12-163\end{array}$ & $\gamma$ & [30] \\
\hline $\begin{array}{l}\text { Hydroquinone } \\
\text { Catechol } \\
\text { DPPD } \\
\text { Dopamine } \\
\text { Aminophenol }\end{array}$ & GCE & $\mathrm{CV}$ & $\begin{array}{c}7.2 \times 10^{-5} \\
41.4 \times 10^{-5} \\
54 \times 10^{-5} \\
17.4 \times 10^{-5} \\
51.6 \times 10^{-5}\end{array}$ & \begin{tabular}{c|}
3.0 \\
10.0 \\
14.0 \\
22.0 \\
50.0
\end{tabular} & $\begin{array}{l}3-150 \\
10-192 \\
14-91 \\
22-262 \\
50-181\end{array}$ & Detection of sulfide performed at $\mathrm{pH} 4$. & [31] \\
\hline Hematoxylin MWCNT & $\mathrm{CPE}$ & Amperometry & $14.6 \times 10^{2}$ & 0.2 & $0.5-150$ & Detection of sulfide performed in river water. & [32] \\
\hline Prussian blue & GCE & Amperometry & $1.35 \times 10^{2}$ & 0.3 & $0.5-100$ & $\begin{array}{l}\text { Detection of sulfide performed in waste water and validated } \\
\text { with independent spectrophotometric method. }\end{array}$ & [1] \\
\hline Nickel oxide & $\begin{array}{l}\text { GCE } \\
\text { SPE }\end{array}$ & LSV & $\begin{array}{l}5.5 \times 10^{3} \\
3.1 \times 10^{3}\end{array}$ & 5.0 & $\begin{array}{r}20-90 \\
40-100\end{array}$ & $\begin{array}{l}\text { Ni modified SPEs demonstrate the possible development of } \\
\text { inexpensive and disposable sensors for sulfide. }\end{array}$ & [33] \\
\hline DMPD & $\mathrm{GCE}, \mathrm{Pt}, \mathrm{CPE}$ and ITO & $\mathrm{CV}$ & $\gamma$ & $\gamma$ & $10-300$ & $\begin{array}{l}\text { DMPD used as electrocatalyst. Various electrode substrates } \\
\text { were used (Pt, ITO, carbon paste), which gave similar response } \\
\text { like GCE. }\end{array}$ & [34] \\
\hline Unmodified & BDDE & Amperometry & $13.03 \times 10^{2}$ & 0.4 & $\gamma$ & Detection performed at in-situ generated $\mathrm{pH} 10$. & [35] \\
\hline Unmodified & $\begin{array}{l}\text { BDDE } \\
\text { BPPGE } \\
\text { EPPGE } \\
\text { GCE }\end{array}$ & $\begin{array}{l}\mathrm{CV} \text { and Square } \\
\text { Wave }\end{array}$ & $1.12 \times 10^{2}$ & 4.9 & $5-60$ & $\begin{array}{l}\text { EPPGE detection compared to a CNT modified GCE, } \\
\text { performed at } \mathrm{pH} 7 \text {. }\end{array}$ & [36] \\
\hline Unmodified & $\begin{array}{l}\text { GCE } \\
\text { SPE }\end{array}$ & $\begin{array}{c}\mathrm{CV} \text { and } \\
\text { Amperometry }\end{array}$ & $\begin{array}{l}1.69 \times 10^{2} \\
1.52 \times 10^{2}\end{array}$ & $\begin{array}{l}37.5 \\
51.8\end{array}$ & $\begin{array}{l}25-400 \\
25-700\end{array}$ & Mediatorless sulfide sensing with unmodified electrodes. & This work \\
\hline
\end{tabular}

$\gamma$ : Value not Stated; DMPD: Dimethyl-4-phenylenediamine; DPSA: Diphenylamine-4-sulfonic acid; DDPS: 4,4'-Diaminodiphenylamine sulfate; DPPD: N,N-Dimethylphenylene1,4-diamine; CNT: Carbon Nanotubes; MWCNT: Multi-Walled Carbon Nanotubes; GCE: Glassy Carbon Electrode; CPE: Carbon Paste Electrode; BDDE: Boron Doped Diamond Electrode; ITO: Indium tin oxide; SPE: Screen-Printed Electrode. 


\section{Results and Discussion}

Throughout the literature there have been an array of studies for the electroanalytical detection of sulfide within aqueous systems, however the majority of these reports focus upon the use of electrocatalysts/mediators for the electrochemical oxidation of sulfide utilizing a variety of molecules, such as ferrocene derivatives, $\mathrm{N}, \mathrm{N}$-diethylphenylene-1,4-diamine, catechol and a plethora of others. Provided within Table 1, is a thorough literature overview where it is apparent that the exploration of bare/unmodified graphite surfaces have been generally overlooked within the academic literature. When unmodified graphite electrodes are utilized, one should benchmark the chosen electrode(s) effectively since its electrochemical history, grade and pretreatment (amongst other things) in the form of polishing can greatly affect its electrochemical performance [37]. To accomplish this, the electrochemical characterization of the edge and basal plane pyrolytic graphite (EPPGE and BPPGE respectively), boron-doped diamond (BDDE), glassy carbon (GCE) and screen-printed electrodes (SPE) were benchmarked using the outer-sphere electrochemical redox probe hexaammineruthenium(III) chloride. This redox probe is sensitive only to the electronic structure of the electrode surface (i.e., proportion of edge plane sites/defects), thus allowing the electrochemical reactivity to be deduced [38]; such benchmarking will allow comparisons to be made within academic literature. The Nicholson method was chosen to estimate the observed standard heterogeneous electron transfer rate, $k^{0}$, for quasi-reversible systems the following expression is utilized [39]:

$$
\varphi=k^{0}[\pi D n v F /(R T)]^{-1 / 2}
$$

where $\phi$ is the kinetic parameter, $D$ is the diffusion coefficient of the electroactive species, $n$ is the number of electrons involved in the process, $F$ is the Faraday constant, $v$ the applied scan rate, $R$ is the universal gas constant, and $T$ is the temperature of the solution at which the experiment is performed. The kinetic parameter, $\phi$ is tabulated as a function of peak-to-peak separation $\left(\Delta E_{\mathrm{P}}\right)$ at a set temperature $(298 \mathrm{~K})$ for a one-step, one electron process. The function of $\phi\left(\Delta E_{\mathrm{P}}\right)$, which fits Nicholson's data, for practical usage (rather than producing a working curve) is given by [40]:

$$
\varphi=(-0.628+0.0021 X) /(1-0.017 X)
$$

where $X=\Delta E_{\mathrm{P}}$, is used to determine $\phi$ as a function of $\Delta E_{\mathrm{P}}$ from the experimentally obtained voltammetry. From this, a plot of $\phi$ against $[\pi D n v F /(R T)]^{-1 / 2}$ can be readily produced graphically allowing the standard heterogeneous rate transfer constant, $k^{0}$, to be readily determined, however $\Delta E_{\mathrm{P}}$ values that exceed $212 \mathrm{mV}$ using the Nicholson method have to rely upon the following equation [41]:

$$
k^{0}=\left[2.18(D \alpha n F v / R T)^{0.5}\right] \exp ^{\left[-\left(\left(a^{2} n F\right) / R T\right) \times \Delta E p\right]}
$$

where the constants are the same as described in Equation (1); however, $\alpha$ is assumed to correspond to 0.5 . The heterogeneous electron transfer rates were calculated assuming a $D$ value of $9.10 \times 10^{-6} \mathrm{~cm}^{2} \cdot \mathrm{s}^{-1}$ [42] using the hexaammineruthenium(III) chloride redox probe; this probe was chosen since it is an outer-sphere redox probe, which is insensitive to the $\mathrm{C} / \mathrm{O}$ ratio groups and is affected only by the electronic structure (i.e., edge plane like-sites/defects) [43], where $k^{0}$ values for the SPE, EPPGE, GCE, BDDE and BPPGE were found to correspond to $8.97 \times 10^{-3}, 5.63 \times 10^{-3}$, $4.67 \times 10^{-3}, 3.92 \times 10^{-3}$ and $3.69 \times 10^{-3} \mathrm{~cm} \cdot \mathrm{s}^{-1}$, respectively. This places the electrodes in the following order of reactivity: SPE $>$ EPPGE $>$ GCE $>$ BDDE $>$ BPPGE. It is noted that the value for the SPEs are consistent with those in previous literature [44-46]. As the peak-to-peak separations for these carbon based electrodes are similar when utilizing hexammineruthenium(III) chloride, (Table 2) further benchmarking was undertaken using the $\mathrm{Fe}^{2+} / \mathrm{Fe}^{3+}$ redox couple, since this is an inner-sphere probe that is known to be extremely sensitive to surface orientated functional groups, especially carbonyl groups. It is apparent that there is a clear distinction between each electrode material, due to their 
differences within C/O surface groups. Table 2 presents that the order reactivity is EPPG $>$ GCE $>$ SPE $>$ BPPG > BDDE.

Table 2. Comparison of peak potentials for the electrodes used throughout towards $1 \mathrm{mM}$ hexammineruthenium(III) chloride $/ 0.1 \mathrm{M} \mathrm{KCl}$ and $1 \mathrm{mM}$ ammonium iron(II) sulfate $/ 0.2 \mathrm{M} \mathrm{HClO}_{4}$. Scan rate: $50 \mathrm{mV} \cdot \mathrm{s}^{-1}$.

\begin{tabular}{ccc}
\hline \multirow{2}{*}{ Electrode } & \multicolumn{2}{c}{ Analyte } \\
\cline { 2 - 3 } & \multicolumn{3}{c}{ Hexammineruthenium(III) Chloride } & Ammonium Iron(II) Sulfate \\
\cline { 2 - 3 } & $\Delta E \mathbf{p} / \mathbf{m V}$ & $\Delta E \mathbf{p} / \mathbf{m V}$ \\
\hline EPPGE & 76 & 117 \\
BPPGE & 150 & 964 \\
GCE & 86 & 537 \\
SPE & 115 & 605 \\
BDDE & 120 & 1162 \\
\hline
\end{tabular}

Following the electrochemical benchmarking of the graphitic electrodes, focus was next turned to exploring the electrochemical oxidation of sulfide. The detection of sulfide is dependent upon the $\mathrm{pH}$ of solution, at $\mathrm{pH} 7$ the following equilibrium is established and the concentration of mono-protonated sulfide anion dominates $\mathrm{H}_{2} \mathrm{~S} \rightarrow \mathrm{HS}^{-}+\mathrm{H}^{+}(\mathrm{pKa}=6.88)$. The oxidation peak can be attributed to the direct oxidation of the mono -protonated sulfide anion to sulfur, $\mathrm{HS}^{-} \rightarrow \mathrm{S}+2 \mathrm{e}^{-}+\mathrm{H}^{+}$[22]. Figure $1 \mathrm{~A}$ provides a comparison of the current densities for each of the chosen electrodes, with the corresponding peak potentials (maxima of the electrochemical oxidation peak): $+0.35 \mathrm{~V}$ (SPE), $+0.40 \mathrm{~V}$ (GCE), $+0.43 \mathrm{~V}$ (EPPGE) and $+0.84 \mathrm{~V}$ (BDDE) (vs. SCE). It is important to note, that the BPPGE did not present any electrochemical activity towards sulfide, due to the lack of edge sites upon its surface. Overall, it can be concluded that the current densities, peak currents/analytical signals and potentials are comparable for the SPE and GCE; Figure 1B presents the voltammetric responses for the electrochemical oxidation of sulfide utilizing a GCE and a SPE. It can be readily observed from Figure 1 that the GCE and SPE provides optimal electrochemical responses and are the best candidates to further explore the electroanalytical sensing of sulfide. Interestingly our observation that the GCE provides a useful electrochemical response does not agree with reports within the literature. Lawrence et al. [36] report the ineffectiveness of GCE towards the detection of sulfide, and state "the ill-defined oxidation peaks" presented [36]. This again reiterates the need for benchmarking of electrodes utilized within a study, as the electrochemical history, grade and pretreatment (amongst other things) of the underlying electrode is paramount to its electrochemical reactivity and performance to critically allow comparisons to be made within the literature.

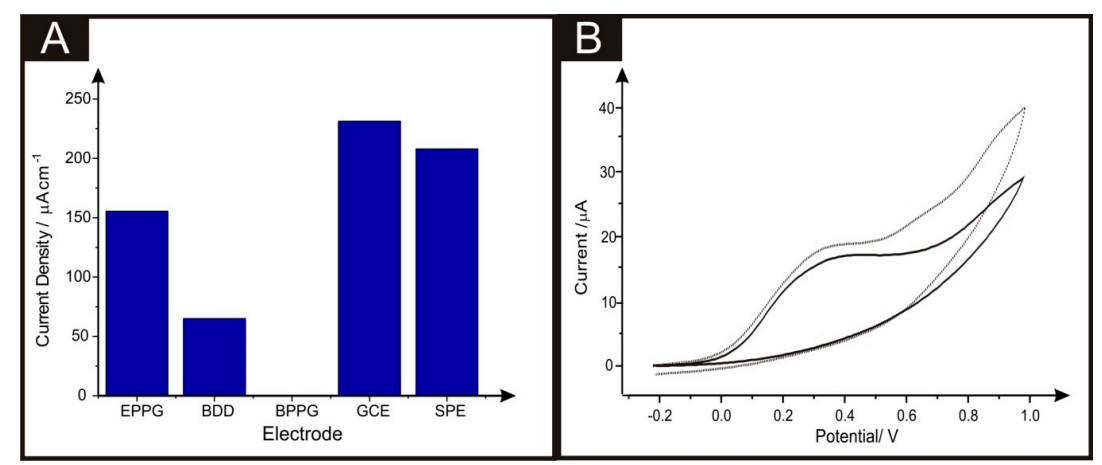

Figure 1. A comparative bar chart (A) of the current densities of the various carbon-based electrodes explored in this study and respective cyclic voltammograms (B) of a SPE (solid line) and GCE (dashed line) recording in a solution comprising of $1 \mathrm{mM}$ sulfide/ $\mathrm{pH} 8$ Britton-Robinson buffer. Scan rate: $100 \mathrm{mV} \cdot \mathrm{s}^{-1}$. 
Due to the GCE and SPE providing the best electrochemical reactivity (see Figure 1) towards the oxidation of sulfide, these were explored towards the electroanalytical detection of sulfide; note again we believe this is the first time that bare/unmodified/mediatorless SPEs have been utilized. Upon utilization of the GCE it was found that the electrode was susceptible to electrode passivation. To exemplify this point, cyclic voltammograms were recorded in the presence of $1 \mathrm{mM}$ sulfide $/ \mathrm{pH} 7$ over a range of scan rates $\left(5-1000 \mathrm{mV} \cdot \mathrm{s}^{-1}\right)$ where the voltammetric peak current $\left(I_{\mathrm{p}}\right)$ was plotted as a function of scan rate $\left(I_{p} v s . v^{1 / 2}\right)$. In the case where the GCE was polished between voltammetric scans, a linear response is observed while without polishing the GCE between voltammetric scans there is no linearity. This is further demonstrated in Figure 2 where polishing the GCE before every measurement leads to a sharp oxidation peak and large peak current where the unpolished counterpart exhibits a small peak current where this electrochemically slow response can be attributed to sulfide adsorption upon the electrode surface, which in-turn decreases the availability of active sites on the GCE and the consequently the voltammetric signal is significantly reduced. These results demonstrate that polishing has a decisive effect upon determination of sulfide using bare GCEs, suggesting that upon the clean and polished surface of GCE the oxidation of sulfide is diffusion controlled, as opposed to being obstructed due to the surface adsorption of sulfide. It can be deduced that upon polishing the GCE, the surface is regenerated therefore improving its response to sulfide sensing. We infer that the poor voltammetric response reported by Lawrence et al. [36] is likely due to surface passivation, which resulted in the authors not considering the GCE further. Note that in respect to SPEs, the effect of the sulfide adsorption was not a consideration as the nature of these electrochemical platforms allow for a one-shot analytical sensor to be realized such that for each voltammetric scan/analytical measurement, a new electrode can be used.

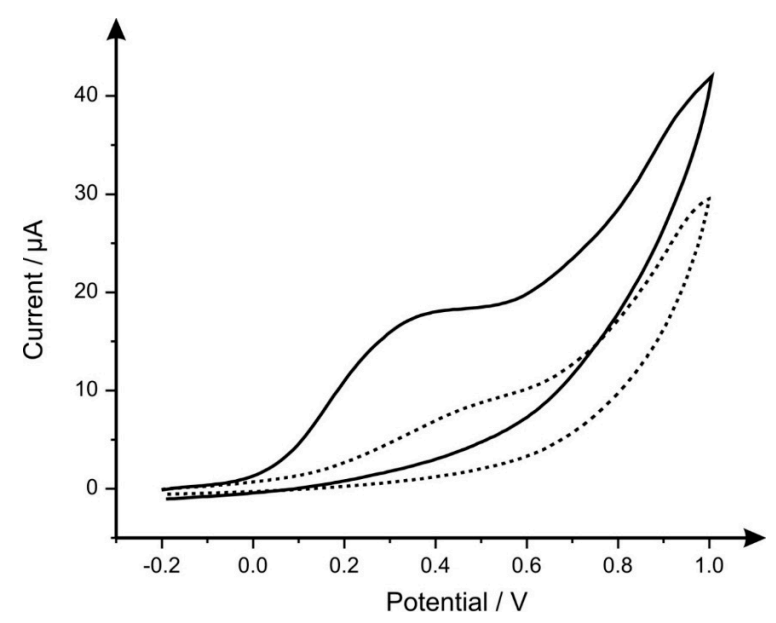

Figure 2. Typical cyclic voltammograms for an unpolished (dashed line) and polished GCE (solid line) solution composition: $1 \mathrm{mM}$ sulfide/pH 7 Britton-Robinson buffer. Scan rate: $100 \mathrm{mV} \cdot \mathrm{s}^{-1}$.

To further explore the novel use of SPEs for the sensing of sulfide, the optimization of the solution $\mathrm{pH}$ was next considered. Depicted within Figure $3 \mathrm{~A}$ are cyclic voltammetric profiles revealing oxidation potentials for sulfide varying from +0.15 to $+0.45 \mathrm{~V}$ (vs. SCE) over a $\mathrm{pH}$ range of 2.5-11. There is a considerable increase within both the peak current and potential, when the $\mathrm{pH}$ of solution increases from $\mathrm{pH} 5$ to $6(\mathrm{pKa}=6.88)$, whereas, above $\mathrm{pH} 6$, both the peak potential and current remain constant. The optimum response observed (Figure 3B) for sulfide sensing with respect to peak current is obtained at $\mathrm{pH} 8$. 


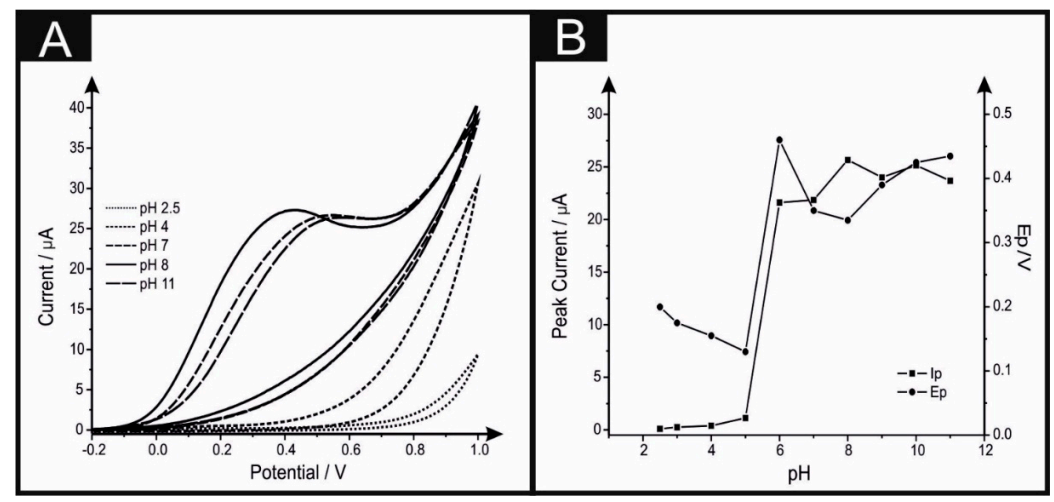

Figure 3. Typical cyclic voltammograms (A) recorded in a $1 \mathrm{mM}$ sulfide using SPEs over a range of $\mathrm{pH}$ 2.5 to 11 . Scan rate: $100 \mathrm{mV} \cdot \mathrm{s}^{-1}$. Shown in (B) are corresponding plots of peak current and potential at each $\mathrm{pH}$. Each data point represents a new SPE used each time.

Next, the electroanalytical capabilities of the GCE and SPE were considered towards the sensing of sulfide. Calibration plots derived from the voltammetric oxidation of sulfide emphasize that polishing makes a remarkable improvement within the sensitivity of the GCE for sulfide sensing over that of the SPE (Figure 4), however it is noticeable that the error bars using the GCE become larger at higher concentrations, which is likely due to more material becoming adsorbed onto the electrode surface and the resultant electrode polishing is not adequate, or repeatable. Note that for the SPEs, a new one was used for each measurement/concentration. The analytical parameters of GCE and SPE are overviewed within Table 3, with the polished GCE showing a slightly higher amperometric sensitivity and wider linear range than that of the SPE. To analyze the analytical performance further, the limit of detection $(3 \sigma)$ was calculated for both the polished GCE and the SPE with values corresponding to $37.5 \mu \mathrm{M}$ and $32.5 \mu \mathrm{M}$ respectively. In summary, the SPE provide a comparable alternative to the GCE without the requirement of electrode polishing. Note that the deduced values for the limit of detection indicate that the SPE mediatorless sensing platform is not as effective as its modified counterparts (see Table 1), however the methodology presented in this report bases a comparison upon unmodified electrode graphitic surfaces, and for the first time envisages the utilizing of a SPE system for the detection of sulfide. Overall, these low cost and disposable SPEs have more advantages over GCE as they give rise to highly reproducible results such that the possibility of erroneous readings due to any contamination from previously absorbed species is eliminated.

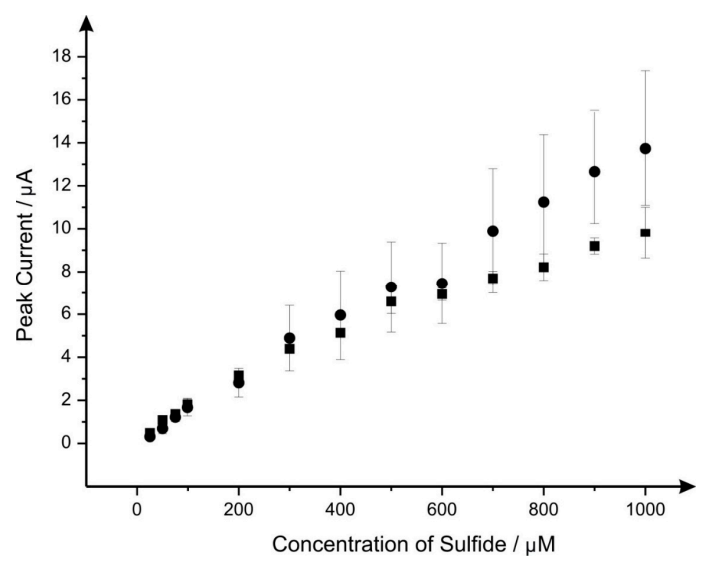

Figure 4. Comparative calibration curves for the polished GCE (circles) and SPEs (squares) over a sulfide concentration range of $25-1000 \mu \mathrm{M}$ in a pH 8 Britton-Robinson buffer solution composition. Scan rate: $100 \mathrm{mV} \cdot \mathrm{s}^{-1}$. Error bars represent average $(n=3)$ and standard deviation. Note: A new SPE was used after every addition; further, each data point for the GCE is following electrode polishing. 
Table 3. Analytical parameters using GCE and SPE for the sensing of sulfide.

\begin{tabular}{ccccc}
\hline Electrode & Slope $/ \mu \mathbf{A} \cdot \mathbf{m M}^{-\mathbf{1}}$ & Sensitivity $/ \mu \mathbf{A} \cdot \mathbf{m M}^{-\mathbf{1}} \cdot \mathbf{c m}^{-\mathbf{2}}$ & $\begin{array}{c}\text { Linear } \\
\text { Range } / \mu \mathbf{M}\end{array}$ & LOD $/ \mu \mathbf{M}$ \\
\hline SPE & 10.755 & 152.23 & $25-700$ & 32.5 \\
GCE-Unpolished & 6.0880 & 86.170 & $25-400$ & 51.8 \\
GCE-Polished & 11.989 & 169.69 & $25-1000$ & 37.5 \\
\hline
\end{tabular}

${ }^{*}$ LOD: Limit of detection based upon $3 \sigma$.

Last, to explore the electroanalytical utility of the SPEs, the electrochemical sensing of sulfide was explored within drinking (tap) water samples. For this purpose, recovery studies were performed within modified drinking (tap) water samples (see Experimental Section). It is important to note that the voltammetric result for sulfide within the real sample was negligible, i.e., lower than the limit of detection for this method, therefore the drinking (tap) water was spiked with various concentrations of sulfide (as reported within Table 4), which were detected using the standard addition protocol. It is clear from inspection of Table 4 that acceptable recoveries of sulfide are achieved, with relative standard deviation (RSD) values of no more than $3 \%(n=3)$ obtained in all cases indicating suitability of the SPEs for the practical application of the sensing of sulfide in aqueous media.

Table 4. Recovery experiments with SPEs for the sensing of sulfide in drinking (tap) water.

\begin{tabular}{ccccc}
\hline Experiment Number & Spiked $/ \mu \mathbf{M}$ & Detected/ $\boldsymbol{M} \mathbf{M}$ & \% RSD $(\boldsymbol{n}=\mathbf{3})$ & \% Apparent Recovery \\
\hline 1 & 50 & $51( \pm 0.005)$ & 0.52 & 101.6 \\
2 & 150 & $148( \pm 0.007)$ & 0.79 & 98.8 \\
3 & 650 & $630( \pm 0.018)$ & 1.81 & 96.9 \\
\hline
\end{tabular}

\section{Materials and Methods}

All chemicals used were of analytical grade and were used as received without any further purification and were obtained from Sigma-Aldrich (Dorset, UK). The solutions were prepared with deionized water of resistivity not less than $18 \mathrm{M} \Omega \cdot \mathrm{cm}$. Stock sulfide solutions $(0.05 \mathrm{M})$ were prepared from sodium sulfide using degassed phosphate buffer solution (PBS) and used within $4 \mathrm{~h}$ to minimize concentration losses due to aerial oxidation [47].

Voltammetric measurements were carried out using an EmStat [3] potentiostat and controlled by PS Trace 4.4 software (Houten, Netherlands). All the electrochemical measurements consisted of a three electrode system with a range of working electrodes: glassy carbon electrode (GCE, $3 \mathrm{~mm}$ diameter), edge plane pyrolytic graphite electrode (EPPGE, $4.9 \mathrm{~mm}$ diameter), basal plane pyrolytic graphite electrode (BPPGE, $4.9 \mathrm{~mm}$ diameter) or boron doped diamond electrode (BDDE, $3 \mathrm{~mm}$ diameter), a nickel wire counter and a saturated calomel electrode (SCE) reference electrode to complete the circuit. All electrodes (apart from the BPPGE) were polished with alumina of decreasing sizes (Kemet, Kent, UK), upon soft lapping pads, in the case of the BPPGE cleaving with "sticky-tape" was utilized.

The screen-printed electrodes (SPEs) (3 mm working electrode diameter) were fabricated in-house (as described in the previous reports) [24,25] utilizing appropriate stencil designs using a microDEK 1760RS screen-printing machine (DEK, Weymouth, UK). A previously used carbon-graphite ink formulation (Product Code: C2000802P2; Gwent Electronic Materials Ltd., Gwent, UK) was first screen-printed onto a polyester flexible film (Autostat, 250 micron thickness) [44,48]. This layer was cured in a fan box oven (with a fan and extraction) at $60^{\circ}$ for $30 \mathrm{~min}$. Next a silver/silver chloride reference electrode was included by screen-printing Ag/ $\mathrm{AgCl}$ paste (Product Code: C2040308P2; Gwent Electronic Materials Ltd.) onto the polyester substrate. A dielectric paste/ink (Product Code: D2070423D5; Gwent Electronic Materials Ltd.) was next printed to cover the connections and define the carbon-graphite working electrode ( $3 \mathrm{~mm}$ diameter), after curing the electrodes were connected via an edge connector to ensure a secure electrical connection [49]. The SPEs fabricated here have been 
extensively characterized via RAMAN, X-ray Photoelectron Spectroscopy (XPS) and Scanning Electron Microscopy (SEM) analysis and published within recent literature [50].

Drinking (tap) water was obtained from a drinking water tap (Manchester City Centre, Manchester, UK), which was run for a minute before a sample was obtained. The sample was then modified 1:1 with $\mathrm{pH} 7 \mathrm{PBS}$. The sample was stored at room temperature and used within a day of sampling.

\section{Conclusions}

The mediatorless electroanalytical sensing of sulfide is reported for the first time at SPEs, which is shown to alleviate issues of surface passivation that limit the use of GCE, since, in the latter, electrode polishing is required before measurements to maintain electrochemical reactivity, where in the former, there is no need for such pretreatment as these SPEs can be used as one-shot disposable sensors due to their low cost. The electroanalytical utility of SPEs is further explored with the detection of sulfide within drinking (tap) water samples, with acceptable apparent recovery values, justifying the plausibility of graphitic mediatorless screen-printed platform as a potential sensor for the sensing of sulfide in aqueous media.

Acknowledgments: We acknowledge the support of the Analytical Chemistry Trust Fund of the Royal Society for a Developing World Scholarship Grant for Bhawana Thakur and a British Council Institutional Link grant (No. 172726574). Elena Bernalte acknowledges funding from Junta de Extremadura (Spain, PO 14021).

Author Contributions: Christopher W. Foster, Craig. E. Banks and Shilpa N. Sawant conceived and designed the experiments; Bhawana Thakur performed the experiments; Jamie P. Smith and Elena Bernalte analyzed the data; Patricia E. Linton and Shilpa N. Sawant contributed reagents/materials/analysis tools; All authors have written the paper.

Conflicts of Interest: The authors declare no conflict of interest.

\section{References}

1. Ertek, B.; Vu, D.L.; Cervenka, L.; Dilgin, Y. Flow injection amperometric detection of sulfide using using a prussian blue modified glassy carbon electrode. Anal. Sci. 2012, 28, 1075-1080. [CrossRef] [PubMed]

2. Radford-Knoery, J.; Cutter, G.A. Determination of carbonyl sulfide and hydrogen sulfide species in natural waters using specialized collection procedures and gas chromatography with flame photometric detection. Anal. Chem. 1993, 65, 976-982. [CrossRef]

3. Colon, M.; Iglesias, M.; Hidalgo, M.; Todoli, J.L. Sulfide and sulfate determination in water samples by means of hydrogen sulfide generation-inductively coupled plasma-atomic emission spectrometry. J. Anal. At. Spectrom. 2008, 23, 416-418. [CrossRef]

4. Sosa, V.; Barceló, C.; Serrano, N.; Ariño, C.; Díaz-Cruz, J.M.; Esteban, M. Antimony film screen-printed carbon electrode for stripping analysis of $\mathrm{Cd}(\mathrm{II}), \mathrm{Pb}(\mathrm{II})$, and $\mathrm{Cu}(\mathrm{II})$ in natural samples. Anal. Chim. Acta 2015, 855, 34-40. [CrossRef] [PubMed]

5. Bailey, T.S.; Pluth, M.D. Chemiluminiscent detection of enzimatically produced hydrogen sulfide: substrate hydrogen bonding influences selectivity for $\mathrm{H}_{2} \mathrm{~S}$ over biological thiols. J. Am. Chem. Soc. 2013, 135, 16697-16704. [CrossRef] [PubMed]

6. Lawrence, N.S.; Davis, J.; Compton, R.G. Analytical strategies for the detection of sulfide: a review. Talanta 2000, 52, 771-784. [CrossRef]

7. Pandey, S.K.; Kim, K.-H.; Tang, K.-T. A review of sensor-based methods for monitoring hydrogen sulfide. TrAC Trends Anal. Chem. 2012, 32, 87-99. [CrossRef]

8. Figueiredo-Filho, L.C.S.; Brownson, D.A.C.; Fatibello-Filho, O.; Banks, C.E. Exploring the origins of the apparent "electrocatalytic" oxidation of kojic acid at graphene modified electrodes. Analyst 2013, 138, 4436-4442. [CrossRef] [PubMed]

9. Brownson, D.A.C.; Foster, C.W.; Banks, C.E. The electrochemical performance of graphene modified electrodes: An analytical perspective. Analyst 2012, 137, 1815-1823. [CrossRef] [PubMed]

10. Ramdani, O.; Metters, J.P.; Figueiredo-Filho, L.C.S.; Fatibello-Filho, O.; Banks, C.E. Forensic electrochemistry: Sensing the molecule of murder atropine. Analyst 2013, 138, 1053-1059. [CrossRef] [PubMed] 
11. Brownson, D.A.C.; Banks, C.E. Graphene electrochemistry: Fabricating amperometric biosensors. Analyst 2011, 136, 2084-2089. [CrossRef] [PubMed]

12. Hernández-Ibáñez, N.; García-Cruz, L.; Montiel, V.; Foster, C.W.; Banks, C.E.; Iniesta, J. Electrochemical lactate biosensor based upon chitosan/carbon nanotubes modified screen-printed graohite electrodes for the determination of lactate in embryonic cell cultures. Biosens. Bioelectron. 2016, 77, 1168-1174. [CrossRef] [PubMed]

13. Brownson, D.A.C.; Gorbachev, R.V.; Haigh, S.J.; Banks, C.E. CVD graphene vs. highly ordered pyrolitic graphite for use in electroanalytical sensing. Analyst 2012, 137, 833-839. [CrossRef] [PubMed]

14. Thakur, B.; Bernalte, E.; Smith, J.P.; Foster, C.W.; Linton, P.E.; Sawant, S.N.; Banks, C.E. Utilising copper screen-printed electrodes (CuSPE) for the electroanalytical sensing of sulfide. Analyst 2016, 141, 1233-1238. [CrossRef] [PubMed]

15. Hart, J.P.; Wring, S.A. Screen-printed voltammetric and amperometric electrochemical sensors for decentralized testing. Electroanalysis 1994, 6, 617. [CrossRef]

16. Li, M.; Li, Y.; Li, D.; Long, Y. Recent developments and applications of screen-printed electrodes in environmental assays-A review. Anal. Chim. Acta 2011, 734, 31. [CrossRef] [PubMed]

17. Kumar, A.S.; Zen, J. Electrochemical investigation of glucose sensor fabricated at copper-plated screen-printed carbon electrodes. Electroanalysis 2002, 14, 671. [CrossRef]

18. Honeychurch, K.C.; Hart, J.P. Screen-printed electrochemical sensors for monitoring metal pollutants. TrAC Trends Anal. Chem. 2003, 22, 456. [CrossRef]

19. De Souza, A.P.R.; Foster, C.W.; Kolliopoulos, A.V.; Bertotti, M.; Banks, C.E. Screen-printed back-to-back electroanalytical sensors: Heavy metal ion sensing. Analyst 2015, 140, 4130-4136. [CrossRef] [PubMed]

20. Smith, J.P.; Metters, J.P.; Kampouris, D.K.; Lledo-Fernandez, C.; Sutcliffe, O.B.; Banks, C.E. Forensic electrochemistry: The electroanalytical sensing of Rohypnol ${ }^{\circledR}$ (flunitrazepam) using screen-printed graphite electrodes without recourse for electrode or sample pre-treatment. Analyst 2013, 138, 6185-6191. [CrossRef] [PubMed]

21. Ruas de Souza, A.P.; Bertotti, M.; Foster, C.W.; Banks, C.E. Back-to-back screen-printed electroanalytical sensors: Extending the pottential applications of the simplistic design. Electroanalysis 2015, 27, 2295-2301. [CrossRef]

22. Robinson, K.L.; Lawrence, N.S. A vinylanthracene and vinylferrocene-containing copolymer: A new dual $\mathrm{pH}$ /sulfide sensor. Electroanalysis 2006, 18, 677-683. [CrossRef]

23. Lawrence, N.S. Amperometric detection of sulfide: An electrocatalytic reactiuon with ferrocene carboxylate. Electroanalysis 2006, 18, 1658-1663. [CrossRef]

24. Dilgin, Y.; Kizilkaya, B.; Ertek, B.; Eren, N.; Dilgin, D.G. Amperometric detection of sulfide based on its elecctrocatalytic oxidation at a pencil graphite electrode modified with quercetin. Talanta 2012, 89, 490-495. [CrossRef] [PubMed]

25. Prodromidis, M.I.; Veltsistas, P.G.; Karayannis, M.I. Electrochemical study of chemically modified and screen-printed graphite electrodes with $\left[\mathrm{Sb}^{\mathrm{V}} \mathrm{O}(\mathrm{CHL})_{2}\right]$ Hex. Application for the selective determination of sulfide. Anal. Chem. 2000, 72, 3995-4002. [CrossRef] [PubMed]

26. Lawrence, N.S.; Tustin, G.J.; Faulkner, M.; Jones, T.G.J. Ferrocene sulfonates as electrocatalysts for sulfide detection. Electrochim. Acta 2006, 52, 499-503. [CrossRef]

27. Chang, J.-L.; Wei, G.-T.; Chen, T.-Y.; Zen, J.-M. Highly stable polymeric ionic liquid modified electrode to immobilize ferricyanide for electroanalysis of sulfide. Electroanalysis 2013, 25, 845-849. [CrossRef]

28. Lawrence, N.S.; Deo, R.P.; Wang, J. Electrochemical determination of hydrogen sulfide at carbon nanotube modified electrodes. Anal. Chim. Acta 2004, 517, 131-137. [CrossRef]

29. Banks, C.E.; Yashina, A.S.; Tustin, G.J.; Lafitte, V.G.H.; Jones, T.G.J.; Lawrence, N.S. Exploring alkylated ferrocene sulfonates as electrocatalysts for sulfide detection. Electroanalysis 2007, 19, 2518-2522. [CrossRef]

30. Lawrence, N.S.; Davis, J.; Jiang, L.; Jones, T.G.J.; Davies, S.N.; Compton, R.G. Electrochemically initiated reactions of dyphenilamines with sulfide: Application to the voltammetric detection of hydrogen sulfide. Electroanalysis 2001, 13, 143-148. [CrossRef]

31. Lawrence, N.S.; Davis, J.; Jiang, L.; Jones, T.G.J.; Davies, S.N.; Compton, R.G. Electrochemically initiated 1,4-nucleophilic substitutions: A general strategy for the analytical detection of hydrgen sulfide. Electroanalysis 2001, 13, 432-436. [CrossRef] 
32. Long Vu, D.; Červenka, L. Determination of sulfide by hematoxylin multiwalled carbon nanotubes modified carbon paste electrodes. Electroanalysis 2013, 25, 1967-1973. [CrossRef]

33. Giovanelli, D.; Lawrence, N.S.; Wilkins, S.J.; Jiang, L.; Jones, T.G.J.; Compton, R.G. Anodic stripping voltammetry of sulphide at a nickel film: Towards the development of a reagentless sensor. Talanta 2003, 61, 211-220. [CrossRef]

34. Lawrence, N.S.; Davis, J.; Jiang, L.; Jones, T.G.J.; Davies, S.N.; Compton, R.G. The electrochemical analog of the methylene blue reaction: A novel amperometric approach to the detection of hydrogen sulfide. Electroanalysis 2000, 12, 1453-1460. [CrossRef]

35. Bitziou, E.; Joseph, M.B.; Read, T.L.; Palmer, N.; Mollart, T.; Newton, M.E.; Macpherson, J.V. In situ optimization of $\mathrm{pH}$ for parts-per-billion electrochemical detection of dissolved hydrogen sulfide using boron doped diamond flow electrodes. Anal. Chem. 2014, 86, 10834-10840. [CrossRef] [PubMed]

36. Lawrence, J.; Robinson, K.L.; Lawrence, N.S. Electrochemical determination of sulfide at various carbon substrates: A comparative study. Anal. Sci. 2007, 23, 673-676. [CrossRef] [PubMed]

37. Brownson, D.A.C.; Kelly, P.J.; Banks, C.E. In situ electrochemical characterisation of graphene and various carbon-based electrode materials: An internal standard approach. RSC Adv. 2015, 5, 37281-37286. [CrossRef]

38. Brownson, D.A.C.; Varey, S.A.; Hussain, F.; Haigh, S.J.; Banks, C.E. Electrochemical properties of CVD grown pristine graphene: Monolayer- vs. quasi-graphene. Nanoscale 2014, 6, 1607-1621. [CrossRef] [PubMed]

39. Nicholson, R.S. Theory and application of cyclic voltammetry for measurement of electron reaction kinetic. Anal. Chem. 1965, 37, 1351. [CrossRef]

40. Tan, F.; Metters, J.P.; Banks, C.E. Electroanalytical applications of screen printed microelectrode arrays. Sens. Actuators B Chem. 2013, 181, 454. [CrossRef]

41. Lavagnini, I.; Antiochia, R.; Magno, F. An extended method for the practical evaluation of the standard rate constant from cyclic voltammetric data. Electroanalysis 2004, 16, 505. [CrossRef]

42. Banks, C.E.; Compton, R.G.; Fisher, A.C.; Henley, I.E. The transport limited currents at insonated electrodes. Phys. Chem. Chem. Phys. 2004, 6, 3147-3152. [CrossRef]

43. Cumba, L.R.; Foster, C.W.; Brownson, D.A.C.; Smith, J.P.; Iniesta, J.; Thakur, B.; Carmo, D.R.D.; Banks, C.E. Can the mechanical activation (polishing) of screen-printed electrodes enhance their electroanalytical response? Analyst 2016. [CrossRef] [PubMed]

44. Foster, C.W.; Metters, J.P.; Kampouris, D.K.; Banks, C.E. Ultraflexible screen-printed graphitic electroanalytical sensing platforms. Electroanalysis 2014, 26, 262-274. [CrossRef]

45. Rowley-Neale, S.J.; Brownson, D.A.C.; Smith, G.C.; Sawtell, D.A.G.; Kelly, P.J.; Banks, C.E. 2D nanosheet molybdenum disulphide $\left(\mathrm{MoS}_{2}\right)$ modified electrodes explored towards the hydrogen evolution reaction. Nanoscale 2015, 7, 18152-18168. [CrossRef] [PubMed]

46. Randviir, E.P.; Brownson, D.A.C.; Metters, J.P.; Kadara, R.O.; Banks, C.E. The fabrication, characterisation and electrochemical investigation of screen-printed graphene electrodes. Phys. Chem. Chem. Phys. 2014, 16, 4598-4611. [CrossRef] [PubMed]

47. Giovanelli, D.; Lawrence, N.S.; Jiang, L.; Jones, T.G.J.; Compton, R.G. Amperometric determination of sulfide at pre-oxidized nickel electrode in acidic media. Analyst 2003, 128, 173-177. [CrossRef] [PubMed]

48. Foster, C.W.; Metters, J.P.; Banks, C.E. Ultra flexible paper based electrochemical sensors: effect of mechanical contortion upon electrochemical performance. Electroanalysis 2013, 25, 2275-2282. [CrossRef]

49. Galdino, F.E.; Foster, C.W.; Bonacin, J.A.; Banks, C.E. Exploring the electrical wiring of screen-printed configurations utilised in electroanalysis. Anal. Methods 2015, 7, 1208-1214. [CrossRef]

50. Gomis-Berenguer, A.; Gomez-Mingot, M.; Montiel, V.; Canals, A.; Thiemann, T.; Kadara, R.O.; Banks, C.E.; Iniesta, J. Exploring the electrochemical behavior of screen printed graphite electrodes in a room temperature ionic liquid. RSC Adv. 2012, 2, 7735-7742. [CrossRef]

(C) 2016 by the authors; licensee MDPI, Basel, Switzerland. This article is an open access article distributed under the terms and conditions of the Creative Commons Attribution (CC-BY) license (http://creativecommons.org/licenses/by/4.0/). 